Archives de sciences sociales des religions

113 | janvier-mars 2001

Varia

\title{
Le Petit Roi d'Amour : entre dévotion privée et politique
}

Sandra La Rocca

\section{(2) OpenEdition}

1 Journals

Édition électronique

URL : http://journals.openedition.org/assr/20182

DOI : 10.4000/assr.20182

ISSN : $1777-5825$

Éditeur

Éditions de l'EHESS

Édition imprimée

Date de publication : 1 avril 2001

Pagination : 5-26

ISBN : 2-222-96701-5

ISSN : 0335-5985

\section{Référence électronique}

Sandra La Rocca, «Le Petit Roi d'Amour : entre dévotion privée et politique », Archives de sciences sociales des religions [En ligne], 113 | janvier-mars 2001, mis en ligne le 03 décembre 2013, consulté le 03 mai 2019. URL : http://journals.openedition.org/assr/20182 ; DOI : 10.4000/assr.20182

Ce document a été généré automatiquement le 3 mai 2019

(C) Archives de sciences sociales des religions 


\title{
Le Petit Roi d'Amour : entre dévotion privée et politique
}

\author{
Sandra La Rocca
}

Dès le début du XVII e siècle, le culte de l'Enfant Jésus, alors tout juste instauré en tant que tel, dévoile son caractère politique. Le cas de Marguerite du Saint-Sacrement est à cet égard explicite. Autour d'une dévotion spécifique à l'Enfant Jésus, un pouvoir royal sur la voie de l'absolutisme et une Église en pleine reconquête des âmes s'imbriquent pour asseoir leur emprise sur la population. Un réseau symbolique complexe lie intimement le céleste Petit Roi de Gloire de Marguerite et le petit Louis XIV. Par l'intermédiaire de son Petit Roi, la carmélite de Beaune œuvre spirituellement pour le Roi et la France ; en retour, la monarchie et l'Église la reconnaissent et légitiment son culte et son action. Il serait également possible d'évoquer pour le XVII ${ }^{\mathrm{e}}$ siècle, si fécond en culte de l'Enfant Jésus, le carme déchaussé François de l'Enfant-Jésus et son engagement auprès du roi d'Espagne, Philippe II; Madame Guyon et son Petit Maître, autour duquel se rassemble une aristocratie dissidente. Dans tous les cas, les différentes dévotions ne sont jamais anodines et leurs implications politiques sont incontestables ${ }^{1}$.

Dans les années 1940, Mère Yvonne-Aimée, une religieuse de Malestroit - un petit village du Morbihan -, instaure avec succès la dévotion toujours vivante au Petit Roi d'Amour. Cette dévotion a tout pour susciter l'étonnement. Elle surgit en plein $\mathrm{XX}^{\mathrm{e}}$ siècle et ressuscite, à la veille du second conflit mondial, un Enfant Jésus dont les principales caractéristiques datent du début de l'époque moderne. Mais en trois siècles, les données sociales et politiques ont radicalement changé. L'État royal est devenu une République, un État laïque ; l'Église et l'État sont officiellement séparés depuis 1905. Par ailleurs, à cette époque, l'Enfant Jésus s'est mué en petit Jésus et appartient à l'univers enfantin. Il est l'Enfant couleur pastel des images pieuses qui exhorte à être sage et obéissant ; il est aussi le poupon des crèches que l'on vient saluer à Noël. Dans ces conditions, que signifie cette dévotion à l'Enfant Jésus qui apparaît dans un contexte politique précis ? D'autre part, audelà du Petit Roi d'Amour, Yvonne-Aimée revêt personnellement une dimension politique. Elle véhicule une idéologie traditionaliste jusqu'aux premières années du second conflit 
mondial, puis rompt brutalement avec elle. Dès lors, il s'agit de cerner la nature du lien entre ces deux facettes a priori disjointes du personnage.

\section{La polémique}

3 Le cas d'Yvonne-Aimée de Malestroit est surprenant à bien des égards. De son vivant, la Mère augustine suscitait à la fois l'admiration la plus inconditionnelle et les réticences les plus vives. Les innombrables manifestations du surnaturel qui accompagnaient son quotidien ont posé problème à l'autorité ecclésiastique déjà engagée dans l'esprit de Vatican II. En 1960, neuf ans après sa mort, le Saint-Office a annoncé l'arrêt définitif du procès de canonisation et l'interdiction formelle de publier des ouvrages sur YvonneAimée de Malestroit. Néanmoins, la rigidité de l'interdit s'est quelque peu relâchée face à la demande. En 1985, l'abbé Laurentin a obtenu l'autorisation exceptionnelle de publier un ouvrage dédié à Mère Yvonne-Aimée; ouvrage réédité en 1995. D'autre part, un énorme recueil composé par le Père Labutte, fidèle ami d'Yvonne-Aimée, a été commercialisé en décembre $1997^{2}$. J'ai pu consulter deux ouvrages publiés en 1956, avant l'interdiction. L'un a été écrit par les sœurs Augustines de Malestroit en l'honneur de leur supérieure ; l'autre a été composé par le Père Barrai en vue de son procès de canonisation. Ils n'apportent pas de révélations supplémentaires par rapport aux livres à présent autorisés, mais restent particulièrement intéressants dans la mesure où ils ont été composés à une époque où la canonisation de Mère Yvonne-Aimée ne faisait aucun doute pour leurs auteurs. Les manifestations du merveilleux sont exposées littéralement, sans dramatisation excessive; et les valeurs de la société d'après-guerre s'expriment librement. Ces ouvrages, autorisés ou non, sont essentiellement des compilations de l'abondante production écrite de Mère Yvonne-Aimée. Elle a laissé de nombreux carnets intimes ainsi qu'une extraordinaire correspondance ${ }^{3}$. Cette bibliographie quelque peu limitée est complétée par des témoignages directs que j'ai pu obtenir à Malestroit même ainsi qu'à Vannes.

4 Il est absolument hors de propos dans cette étude de déterminer le vrai du faux dans le cas d'Yvonne-Aimée de Malestroit. Mon but n'est pas d'apporter une nouvelle pièce à la polémique engagée à son égard de son vivant. Il s'agit d'insérer ce personnage et la dévotion qui lui est attachée dans la problématique annoncée. Commençons par cerner le personnage et les caractéristiques de sa dévotion.

\section{Yvonne Beauvais}

$5 \quad$ Il est particulièrement difficile d'isoler les éléments pertinents pour notre problématique dans la vie d'Yvonne-Aimée tant elle n'est qu'enchevêtrement d'événements aussi hétérogènes que merveilleux. Née le 16 juillet 1901 dans un village de Mayenne, près de Laval, elle vit une enfance quelque peu mouvementée suite à la mort précoce de son père qui oblige sa mère à trouver un emploi d'institutrice. Elle se dépeint comme une enfant fière et capricieuse. «J'étais très bavarde [...] j'étais très coquette [...] j'étais aussi très orgueilleuse et je n'aimais pas les reproches [...] j'étais aussi très gourmande ${ }^{4}$ » se rappelle-t-elle sur son carnet lorsque le Père Crété, son confesseur, lui demande de mettre par écrit ses souvenirs en 1924. Les témoignages montrent une petite fille espiègle, pleine de vie et de bon cœur. Marquée par l'Histoire d'une âme de sainte Thérèse de Lisieux que lui lisait sa grand-mère, elle souhaite ardemment « devenir une sainte » et 
s'applique à réduire «les trois quarts» de ses péchés ${ }^{5}$. L'ouvrage de la célèbre "petite Thérèse " l'accompagne tout au long de la préparation à sa première communion. $\mathrm{Ce}$ temps est l'objet de « beaucoup de grâces ", lit-on, et d'une " avalanche de sacrifices ». Le $1^{\text {er }}$ janvier 1911 elle écrit un pacte de son sang. «Ô mon petit Jésus, je me donne à toi entièrement et pour toujours, je voudrai toujours ce que tu voudras [...]» pose-t-elle solennellement sur le papier, tout juste âgée de neuf ans et demi ${ }^{6}$. Cette écriture au sang est extrêmement valorisée. Les biographes célèbrent le total engagement de la petite fille, y voient un désir précoce de souffrance, une maturité avant l'âge. Sur le plan symbolique, imprimer le papier de son propre sang prend valeur d'engagement indéfectible. La personne qui l'écrit s'implique physiquement dans les phrases écrites, cet acte témoigne d'une soumission du corps ${ }^{7}$. Les textes relatifs à l'enfance d'Yvonne présentent tous les éléments, en quelque sorte, "ordinaires" d'une jeune fille élevée dans un milieu catholique au début de ce siècle qui, à la suite de Thérèse de l'Enfant Jésus, souhaite devenir sainte ${ }^{8}$. La singularité se profile à l'âge adulte.

6 C'est à l'âge de vingt et un ans, que commencent réellement ses visions récurrentes du Christ. Le 5 juillet 1922, elle est pour la première fois en convalescence dans la clinique des Augustines de la Miséricorde de Malestroit, suite à une paratyphoïde, lorsque le Christ fait entendre sa voix et lui annonce sa mission : Porter la Croix. Dès lors, il ne cessera de lui apparaitre, de lui parler, de la conseiller. Son affection envers elle se concrétise par des signes sensibles comme des fleurs - le plus souvent des lys ou des roses -, des bagues d'or et de diamants, des parfums. Toujours le 5 juillet 1922, elle reçoit un lys et l'anneau mystique symbolisant ses « fiançailles spirituelles », alors que le 5 juillet 1941 un lys et un voile marquent son « mariage spirituel». Yvonne-Aimée bénéficie également des dons de prophétie, de guérison, de bilocation, de discernement des esprits, de langues ${ }^{9}$. De son corps émanent des effluves lumineux et odoriférants, des stigmates la marquent à certaines périodes ${ }^{10}$, des médecins attestent le son de deux battements de cœur distincts dans sa poitrine. Nous terminerons cet inventaire non exhaustif en évoquant les « attaques du démon » qui martyrisent incessamment son corps.

7 Dans la tradition mystique, apparaissent le plus souvent des jeunes filles parfaitement policées, contemplatives, qui soumettent leur corps à une ascèse stricte. Yvonne-Aimée aime la vie; elle est gourmande, affectionne la danse et joue du piano. C'est aussi une femme active, particulièrement impliquée dans son temps et douée d'un sens pratique à toutes épreuves. Après son premier séjour à la clinique de Malestroit où elle a la révélation de sa vocation de religieuse, Yvonne-Aimée revient chez les Augustines pour une nouvelle convalescence d'avril à août 1923. Mais l'évêque de Vannes, Monseigneur Gouraud, informé des manifestations «miraculeuses » qui entourent la jeune femme, la convoque, puis la somme de quitter Malestroit avec ordre de cesser toutes relations avec la clinique et la communauté. Alors au Mans, seule et sans ressources, elle n'hésite pas à faire des ménages, à jouer du piano dans des soirées privées, à peindre des images pieuses pour un commerçant du quartier Saint-Sulpice à Paris, elle publie même des romans ${ }^{11}$. Après maintes difficultés, quand elle parvient à intégrer le monastère, elle s'occupe de la restauration de la clinique de Malestroit, met toute son énergie à former les nouvelles recrues de la communauté, est élue supérieure du couvent alors qu'elle n'a que trentetrois ans. Elle mène jusqu'au bout, malgré les réticences du Vatican, son projet de créer la première fédération de couvents de femmes.

$8 \mathrm{Au}$ centre de cette vie mouvementée, une dévotion entièrement élaborée par Mère Yvonne-Aimée : celle du Petit Roi d'Amour. 


\section{Le Petit Roi d'Amour} matin, le Seigneur a béni une branche de rose d'un bouquet que ma petite Mademoiselle [Mlle Bato] m'avait donné pour Le fleurir. Le soir, après le dîner, au moment de donner la rose à ma petite Mademoiselle, je remarque sur la tige quelque chose comme une inscription, mais pas assez nette cependant pour être lue à première vue. Pendant que mademoiselle B., Mère Madeleine et moi, essayons de déchiffrer, nous voyons petit à petit les lettres se former distinctement et apparaître une petite écriture d'un reflet argenté : JÉSUS LE ROI D'AMOUR ». Les trois femmes se recueillent, puis « quelques instants après, avant de se retirer, ma petite Mademoiselle regarda à nouveau la rose qui était restée aux pieds de mon bon Jésus, l'inscription était presque entièrement effacée. Nous demandâmes au bon Jésus de l'écrire à nouveau, ce qu'il fit immédiatement. » Trois jours plus tard, le Christ apparaît à Yvonne-Aimée et lui demande solennellement de dire, et faire dire, matin et soir la prière: "Ô Jésus Roi d'Amour, j'ai confiance en ta miséricordieuse bonté12 $»$.

L'invocation est aussitôt adoptée par la communauté, et plus tardivement indul-genciée par Pie XI. La prière est portée sur un simple signet orné du Cœur embrasé de Jésus. Elle reste limitée aux religieuses de Malestroit, aux malades de la clinique attenante au couvent et à quelques habitants de Malestroit ${ }^{13}$.

11 Pendant dix-huit ans, la dénomination miraculeusement écrite et l'invocation révélée restent sans référent iconographique. C'est seulement à la fin de l'année 1940 que Mère Yvonne-Aimée décide de créer une image et une médaille. Elle exécute alors une série d'aquarelles, et peu à peu, le Roi d'Amour prend corps... il devient l'Enfant Jésus. Il s'agit d'un Christ enfant d'environ six ou sept ans, son visage rond et ses yeux bleus sont encadrés par des cheveux blonds et bouclés. Il porte une couronne d'or surmontée de fleurs de lys sur la tête. Vêtu d'une tunique blanche, il tient une branche d'olivier emblème des Augustines de la Miséricorde - dans sa main gauche, pendant que la main droite montre, au milieu de sa poitrine, son cœur rouge et lumineux.

Matérialisée, la dévotion au Petit Roi d'Amour se propage; et le deuxième conflit mondial lui offre l'occasion de révéler tout son potentiel salvateur. Une femme raconte que la nuit du 15 novembre 1940, des avions survolaient la ville de Rennes où elle résidait. Les vrombissements étaient insupportables, il y avait un «tapage d'enfer ", « quand mes yeux se portèrent sur l'image de Jésus, Roi d'Amour, placée à la tête du lit de maman. » Elle lui demande alors, sans prononcer l'invocation habituelle, de «faire cesser le danger qui plane sur la ville», vœu qui est immédiatement exaucé. Un homme et une femme de Rennes avaient placé une image du Petit Jésus Roi d'Amour dans leur chambre sur les conseils d'une cousine. De fait, leur maison est la seule à être épargnée par les bombardements qui ont touché le quartier. Ils sont nombreux dans la région de Rennes à être « miraculeusement » épargnés par les bombardements pendant les années de conflit. Dans ces quelques témoignages, il semble que ce soit l'image seule qui agisse. Un seul exemple associe l'invocation et l'image pour obtenir une protection contre les bombardements. Mais l'homme ainsi épargné écrit à sa sœur qui lui avait recommandé de réciter la prière : «Vraiment je crois à l'intervention de l'image de Jésus Roi d'Amour, c'est grâce à elle si nous avons été protégés ${ }^{14} »$. Ainsi, une fois concrétisé, matérialisé dans une image, le Roi d'Amour acquiert une irréfutable efficacité auprès des personnes qui 
l'invoquent. Les historiens des religions ont tous souligné que la guerre entrainnait un regain des pratiques religieuses. Les messes sont davantage suivies, les prières et les dévotions se multiplient ${ }^{15}$. Matérialisé dans un contexte propice, le Petit Roi d'Amour bénéficie de cette ferveur collective.

Un constat s'impose à présent. Le Petit Roi d'Amour tel qu'il est dessiné fin décembre 1940 par Yvonne-Aimée ne correspond en rien aux visions récurrentes du Christ qu'elle décrit dans ses carnets. Peu avant sa révélation, le 16 juillet 1922, le Christ lui apparaît ; adulte. Ses yeux sont "assez foncés ", et ses " cheveux châtains à reflets d'or ${ }^{16}$ ». C'est toujours Jésus adulte qu'elle suit des yeux " pendant un quart d'heure » le 9 août suivant. C'est lui enfin qui lui dicte l'invocation. Dans ce contexte, le glissement du Christ adulte au Christ enfant est quelque peu déroutant ${ }^{17}$. Mère Yvonne-Aimée, habituellement si prolixe sur les moindres événements de sa vie, ne s'attarde pas sur les motivations de sa création d'image. Dans un style stéréotypé et froid, peu habituel chez elle, elle précise : « Nous avons représenté Jésus, Enfant et Roi, pour attirer plus facilement les âmes et leur donner confiance et espoir ${ }^{18}$ ». De fait, c'est toujours le Christ adulte qu'elle voit et qui la comble de faveurs. Il faut chercher dans ses souvenirs d'enfance pour trouver une sensibilité particulière à l'Enfant Jésus, mais elle n'est pas significative en soi ${ }^{19}$. En revanche, il est question de façon récurrente dans les écrits d'Yvonne-Aimée, « d'humilité ", d'effort pour " devenir petite ", de volonté de "n'être plus rien par soi-même ", "d'être entièrement dépendante du Christ», «d'abandon», de «renoncement ${ }^{20} »$. Ces termes sont précisément ceux de la « petite voie » de sainte Thérèse de l'Enfant-Jésus et de la SainteFace, bien connue d'Yvonne-Aimée. "L'Abandon est le fruit délicieux de l'Amour " écrivait avec candeur la toute petite sainte; c'est la disposition du "petit enfant qui s'endort sans crainte dans les bras de son Père. » Le seul moyen de se rapprocher de Dieu est de « rester petit », de le « devenir de plus en plus ${ }^{21}$ ».

Dans ces circonstances, on peut penser que le Petit Roi d'Amour de celle qui s'est quelquefois appelée "la toute petite Aimée de Jésus », est porteur d'une spiritualité de l'Enfance d'influence thérésienne. Au contraire, le Père Labutte qui, dans son ouvrage, aborde seulement les conditions de la révélation de la nouvelle dévotion, affirme qu'en dessinant un Enfant Jésus, Yvonne-Aimée ne visait absolument pas une dévotion à l'Enfance du Christ, mais qu'elle voulait seulement montrer un Christ «abordable ${ }^{22} »$. L'observation du Père Labutte est digne d'intérêt et corrobore l'affirmation d'YvonneAimée. Mais, sans vouloir absolument trouver un sens caché à tout, nous prenons le parti de considérer que ce n'est pas un hasard si, au début du deuxième conflit mondial, Yvonne-Aimée décide d'ériger un Enfant Jésus et non le Christ adulte qu'elle « voyait » si souvent. Il convient alors de considérer plus précisément le Petit Roi d'Amour et de rechercher à quels référents symboliques il renvoie dans la mémoire collective.

\section{L’Enfant Jésus : la victime}

15 Le dépouillement de plusieurs séries d'images pieuses montre qu'entre le milieu du XIX siècle et le début du $\mathrm{XX}^{e}$ siècle, la représentation la plus fréquente de l'Enfant Jésus est celle où il est entouré des instruments de la Passion ${ }^{23}$. Il les porte dans ses bras, ou encore dort sur la croix en rêvant à son futur supplice. De surcroît, cet Enfant Jésus à la Passion profère de graves paroles. Un seul exemple suffira pour illustrer le genre qui se répète inlassablement. Une image de communion datant de 1884 est intitulée La première prière de l'Enfant Jésus. Un Enfant Jésus de trois ou quatre ans regarde mélancoliquement vers le 
ciel, il tient la croix et la couronne d'épine; sur le sol repose un panier contenant le marteau, les clous et la tenaille. Au bas de l'image, cette sentence : «Vous m'avez envoyé pour leur apprendre à aimer ... et à souffrir, parce que sur la terre le pur amour n'est plus possible sans souffrance. » Au verso une série de questions/réponses entre l'Enfant Jésus et l'âme. L'âme s'étonne de trouver des croix, des épines et des larmes irrémédiablement accolées à l'amour de Jésus. L'Enfant répond que Dieu lui a donné un corps pour qu'il incarne une "victime pure et innocente", qu'il vient "remplacer les victimes figuratives ", qu'il «s'offre en sacrifice, c'est-à-dire souffrir et mourir pour le péché.» L'âme n'y tient plus, et veut l'accompagner au sacrifice. Le petit Jésus de l'ouvrage de Jean Plaquevent destiné aux enfants, demande pareillement « des petits enfants qui m'aiment assez pour me donner leur vie et ne plus jamais me la reprendre ${ }^{24} »$. L'Enfant Jésus de la crèche n'échappe pas au genre, les jeunes communiants de la première moitié de ce siècle pouvaient voir l'Enfant, couché sur un berceau de paille, tenant la croix. La mignardise des images pieuses ne manque jamais d'être soulignée dans les rares ouvrages qui leur sont consacrés ${ }^{25}$. Cependant cette incontestable mièvrerie recèle de violentes exhortations à la souffrance, au malheur, à la mort. La "spiritualité victimale " se propage auprès des enfants à travers la figure du petit Jésus. Les «innocentes » petites images qu'ils manipulent les invitent individuellement à souffrir pour le Christ.

Le thème de l'Enfant Jésus avec les instruments de la Passion est connu depuis le Moyen Âge, mais ce n'est véritablement qu'au XVII e siècle qu'il passe dans l'iconographie de tous les pays européens. En 1658, l'aixoise Jeanne Perraud voit un Enfant Jésus de trois ans, aux cheveux blonds et à la tunique blanche. Sur son bras gauche repose une énorme croix, à laquelle sont suspendus les instruments de la Passion ${ }^{26}$. La description détaillée de Jeanne devient le point de départ d'un motif iconographique très apprécié par les artistes provençaux. Le thème de l'Enfant Jésus aux instruments de la Passion connaît rapidement un vif succès dans toute l'Europe, pour s'épanouir pleinement à la fin du XIX et dans la première moitié du $\mathrm{XX}^{\mathrm{e}}$ siècle. Cette connexion Enfance/Passion est d'autant plus explicite que, peu après sa vision de l'Enfant Jésus portant la croix, la même Jeanne Perraud voit une nouvelle fois le Christ. Mais, cette fois-ci, il lui apparaît adulte et sanglant. Henri Brémond, dans son imposante Histoire littéraire du sentiment religieux en France, rapproche cette vision de celle de Marguerite-Marie Alacoque en 1675. Il parle alors d'une transition entre le mystère de l'Enfance et celui de la Passion. Pour lui, il est clair que « la dévotion à l'Enfant Jésus n'aura été [...] qu'une sorte d'acheminement à la dévotion de Paray ${ }^{27} »$.

17 L'association Enfance/Passion, qui se matérialise au XVII ${ }^{\mathrm{e}}$ siècle à travers la vision de Jeanne, réactive une pensée du sacrifice très ancienne. En effet, l'iconographie de la Nativité du XII siècle nous montre très clairement l'Enfant Jésus sur un autel et non dans une crèche comme l'indique l'Évangile de Luc. Émile Mâle soulignait que l'iconographie médiévale était ainsi en adéquation avec la Glose qui affirmait que « la crèche où il repose est l'autel même du sacrifice ${ }^{28}$ ». Dès les premiers siècles chrétiens, existe l'idée que l'Enfant est voué au sacrifice dès sa naissance. C'est également sur un autel qu'il est placé dans les drames de la Nativité tels qu'ils étaient joués aux XII ${ }^{e}$ et XIII ${ }^{e}$ siècles. Dans le Drame de la Présentation d'York, par exemple, Marie amène Jésus au Temple et se lamente de ne pas avoir amené d'agneau pour l'offrir en sacrifice comme l'usage le voulait. Joseph la rassure et désigne l'Enfant comme l'agneau ${ }^{29}$.

18 Par ailleurs, en 1215, l'Église proclame le dogme de la transsubstantiation. Dès lors, il s'agit de montrer aux fidèles que le Christ est véritablement présent dans l'hostie 
consacrée. De très nombreux exempla du Moyen Âge ayant pour but de confirmer la présence réelle racontent le miracle d'une hostie transformée en Enfant Jésus ${ }^{30}$. Le Christ enfant « figure » la chair et le sang du Christ dans l'Eucharistie. C'est lui qui apparaît à la place de l'hostie dérobée par une femme noble à des fins magiques. C'est lui encore qui est vu démembré et consommé pendant la messe par des juifs incrédules ${ }^{31}$. Si ce motif perd de sa pertinence dès la fin du XIII ${ }^{\mathrm{e}}$ siècle, il reste profondément ancré dans les consciences et resurgit explicitement à la fin du XIX ${ }^{e}$ siècle. L'Enfant Jésus est à nouveau désigné comme l'hostie dans les images pieuses destinées aux jeunes communiants. Il est donné par Marie au petit communiant, ou encore sort d'un calice. Une image très répandue intitulée L'hostie de Noël représente l'Enfant Jésus en nouveau-né, les bras tendus, sur une hostie.

Comme le souligne Claude Lévi-Strauss, «les coutumes ne disparaissent ni ne survivent sans raison. Quand elles subsistent, la cause ne s'en trouve pas moins dans la viscosité historique que dans la permanence d'une fonction que l'analyse du présent doit permettre de déceler ${ }^{32} »$. Les thèmes de l'Enfant comme victime sacrificielle, de l'Enfance intimement liée à la Passion sont présents en filigrane depuis les premiers siècles chrétiens, tout au long du Moyen Âge, et jusqu'à nos jours, mais ils sont particulièrement pertinents au XVII ${ }^{e}$ siècle dans le contexte de la Réforme catholique, et à la charnière du $\mathrm{XIX}^{\mathrm{e}}$ et $\mathrm{du} \mathrm{XX}^{\mathrm{e}}$ siècle, à un moment où l'Église tente de resserrer son emprise sur une société alors officiellement laïque. Il s'agit de situations où l'Institution catholique est menacée, par le protestantisme au XVII siècle, par les valeurs laïques et républicaines au début du XXe.

\section{Le Cœur de l'Enfant Jésus}

Le Petit Roi blond aux yeux bleus, imaginé par Yvonne-Aimée fin décembre 1940, montre son cœur de sa main droite, nous l'avons dit. Ce cœur figuré est un renvoi tout à fait clair à la dévotion au Sacré-Cœur. La référence devient explicite quand Mère Yvonne-Aimée affirme "nous avons voulu aussi rappeler que c'est par son Divin Cœur, plein de miséricorde et d'amour pour l'humanité, que nous obtiendrons la paix du monde. » Si le cœur de l'aquarelle est celui du Sacré-Cœur, le nom même de l'Enfant Jésus est tout aussi déterminant. Il oscille entre Jésus Roi d'Amour et Petit Roi d'Amour. Or dans la première moitié du XXe siècle, l'expression «Roi d'Amour» désigne normalement le Christ du Sacré-Cœur. Les nombreux opuscules consacrés au culte du Sacré-Cœur mentionnent tous l'idée de « royauté d'amour » du Christ comme un concept communément admis. En 1932, le chanoine L. Henri-Olivier compose un livret pour honorer le Sacré-Cœur tous les jours du mois de juin intitulé Le mois du Roi d'Amour. Les expressions « Jésus Roi d'amour et de miséricorde ", "Jésus Roi d'Amour miséricordieux », reviennent inlassablement tout au long de l'ouvrage ${ }^{33}$. Ainsi quand Yvonne-Aimée lance la formule : « Jésus Roi d'Amour, j'ai confiance en ta miséricordieuse bonté », elle cristallise en une seule phrase tous les termes familiers de la dévotion au Sacré-Cœur. Le vocabulaire choisi et utilisé par Yvonne-Aimée, tant pour l'appellation de son Enfant Jésus que pour l'invocation qui l'accompagne, est donc précisément celui de la célèbre dévotion au Sacré-Cœur. La Mère augustine est imprégnée par son époque ${ }^{34}$.

21 En quoi cette référence au Sacré-Cœur est-elle pertinente ? En fait, le culte du Sacré-Cœur n'est pas une dévotion anodine en cette première moitié $\mathrm{du} \mathrm{XX}^{\mathrm{e}}$ siècle. Précisons que notre propos n'est pas de développer un historique du culte du Sacré-Cœur ${ }^{35}$. Sans entrer 
dans le détail de cette dévotion complexe, nous essayons simplement de dégager les valeurs symboliques attachées à ce cœur rouge et lumineux arboré par l'Enfant Jésus d'Yvonne-Aimée. C'est entre les années 1673 et 1675, à Paray-le-Monial, que le Christ apparait à plusieurs reprises à la visitandine Marguerite-Marie Alacoque. Il lui fait découvrir "les merveilles de son amour et les secrets inexplicables de son sacré Cœur. » Ce Cœur est "passionné d'amour pour les hommes", et désire ardemment être aimé d'eux. Mais en retour, il ne recueille qu' ingratitudes ", " irrévérences ", " sacrilèges ", "froideur» et "indifférences ». L'amour méconnu et bafoué du Christ pour l'espèce humaine demande donc "réparation». Le Christ impose à Marguerite-Marie certains actes de pénitence, et lui demande d'être "sa victime d'immolation ${ }^{36}$ ». Il a besoin de personnes chargées de « réparer » les offenses des hommes. Le culte du Sacré-Cœur parle d'amour, mais un amour dans la souffrance. Avec Marguerite-Marie, cette fin de XVII ${ }^{\mathrm{e}}$ siècle voit se fixer la théologie de la « réparation » et de la «spiritualité victimale ${ }^{37}$ ». Par ailleurs, le Christ demande une "réparation d'honneur " par une " amende honorable " et l'institution d'une fête étendue à l'Eglise universelle pour honorer son Cœur.

Comme toutes les dévotions, celle de Marguerite-Marie s'insère dans le contexte social et religieux de son temps. Louis XIV est alors fortement préoccupé par la Révolution d'Angleterre et la Ligue d'Augsbourg qui menacent le royaume de France. Aussi, quand Marguerite-Marie le somme d'honorer publiquement le Sacré-Cœur et de poser son image sur l'étendard français, ses demandes ont un sens politique précis ${ }^{38}$. Les études les plus récentes doutent que le Roi ait été prévenu ${ }^{39}$. Néanmoins, les " messages à Louis XIV » ne cessent de se propager et sont connus du grand public en 1867, au moment de la première publication des œuvres de Marguerite-Marie. Aussi surprenant que cela puisse paraitre, la dévotion de la Visitandine connait un succès prodigieux presque deux siècles plus tard, "aux prix de nombreuses déformations ", précise Jacques Le Brun. Elle se développe au sein de contextes politiques radicalement différents et une théologie se met en place. La France est considérée comme la nation élue de Dieu et des faits historiquement marquants comme la Révolution française ou la défaite de 1870 sont interprétés a posteriori comme des conséquences du prétendu refus de Louis XIV de faire du Sacré-Cœur un culte public. Cette théologie est vulgarisée par de nombreux opuscules. «Le culte du Sacré-Cœur devenait en France déploration publique des crimes collectifs de la nation » commente Jean-Pierre Albert. La France ne cesse d'expier ses péchés. Le culte réapparaît de façon récurrente dans des circonstances de crise, des situations de «calamités publiques». En 1873, l'Assemblée nationale déclare la construction de la basilique du Sacré-Cœur de Montmartre « d'utilité publique ». Marguerite-Marie est béatifiée en 1864 et canonisée en 1920.

De la fin des années 1860 aux années 1920, le culte du Sacré-Cœur est nettement marqué comme un culte de combat. Il connaît une très large diffusion pendant la Première Guerre mondiale. Il trouve dans le conflit mondial la concrétisation de ses menaces de châtiments collectifs depuis longtemps réitérés. L'adhésion des soldats au culte est largement attestée $e^{40}$. En 1917, Claire Ferchaud entreprend de créer, sous le signe du Sacré-Cœur, une congrégation de victimes volontaires comme il en existe beaucoup en France à cette époque. Plus encore, elle écrit au président de la République Raymond Poincaré et se rend même à Paris pour le rencontrer afin de lui transmettre le message du Sacré-Cœur. L'entrevue n'a aucun effet, et la congrégation est condamnée par le SaintOffice, mais Claire Ferchaud poursuit ses desseins, en marge. Ainsi, trois siècles après les exigences de Marguerite-Marie, les mêmes revendications sont formulées. L'espoir de 
voir la France, « redevenue officiellement chrétienne ", derrière un drapeau national à l'image du Sacré-Cœur court toujours ${ }^{41}$.

Ainsi, en montrant son cœur lumineux, l'Enfant Jésus d'Yvonne-Aimée active donc une idéologie combative qui s'épanouit dans le contexte de la spiritualité victimale et de la réparation. Le Petit Roi d'Amour, par le cœur qu'il arbore et la figuration de l'Enfant Jésus qu'il est, mêle donc deux symboles sacrificiels. Dans les premiers mois du second conflit mondial, il se dresse pour sauver la nation en danger et rétablir l'ordre. Tout comme le culte du Sacré-Cœur, celui de l'Enfant Jésus semble être « une réponse antimoderne à la sécularisation de la société et de l'État et, en même temps, une adaptation à la réalité nouvelle de la nation ${ }^{42} »$.

Gardons-nous cependant de toute conclusion hâtive. En anticipant quelque peu sur la suite, il convient de distinguer dès à présent les décalages certains qui existent entre le culte du Sacré-Cœur et la dévotion au Petit Roi d'Amour promue par Mère Yvonne-Aimée. Tout d'abord, associer le Sacré-Cœur et l'Enfant Jésus n'est pas une nouveauté. Dès la fin du XVIII ${ }^{e}$ siècle, des artistes napolitains exécutaient des Enfants Jésus au Sacré-Cœur. De telles représentations entraient dans les demeures au XIX ${ }^{\mathrm{e}}$ siècle et se diffusaient à grande échelle sous forme d'Enfants Jésus « sous cloche». Par ailleurs, cette association Enfant Jésus/Sacré-Cœur présente des aspects contradictoires : l'Enfant Jésus n'est pas une figure accusatrice comme peut l'être le Christ du Sacré-Cœur ; il n'annonce pas de châtiments futurs, mais se présente au contraire comme une figure protectrice. Notons encore que le Sacré-Cœur appelle des actes " publics » de réparation - le Christ demande une " amende honorable " - ; en revanche l'Enfant Jésus renvoie à des engagements qui restent dans la sphère du "privé ». Ainsi, même s'il reprend dans ses grandes lignes la symbolique du Sacré-Cœur, le culte d'Yvonne-Aimée s'en écarte sensiblement.

\section{Le salut de la France}

La question se pose alors de savoir si Mère Yvonne-Aimée entrait personnellement dans la théologie du Sacré-Cœur mise en place à la fin du XIXe siècle. Reprenons les biographies autorisées. Si elles présentent une petite fille espiègle puis une femme dynamique, elles n'oublient pas un élément récurrent et essentiel de sa vie : la souffrance. Enfant, ce sont de "terribles maux de tête » qui l'empêchent d'étudier correctement. À seize ans, une scarlatine lui impose une longue convalescence. À vingt et un ans, elle est envoyée à la clinique de Malestroit pour soigner une paratyphoïde. Elle transcrit sur son carnet le 11 juillet 1922 les paroles du Christ qui lui affirme : « Je t'aime ma petite Yvonne, et, à tous ceux que j'aime, je n'épargne pas la souffrance, car elle est nécessaire à la sanctification ${ }^{43}$ ». Puis, ce sont des " coups et blessures du démon », des plaies sanglantes qui se forment sous les yeux des sœurs, de terribles douleurs aux reins étreignent. Cette même année 1922, elle se repose à Anglet quand elle fait des « cauchemars effrayants » à répétition. Elle écrit à son confesseur : «Je voyais des avions jeter des gros cylindres sur les trains, sur les gares, et détruire et incendier tout. Je voyais des hommes habillés en vert monter et descendre du train. On aurait dit des costumes militaires [...]. J'avais le cœur serré et j'entendais une voix grave et douce qui disait: ce sera l'épreuve, la grande épreuve. Prie beaucoup pour les prêtres et les prisonniers. Je me suis réveillée en sursaut ». Ces visions prophétiques décrivent avec précision la Deuxième Guerre mondiale. «Sur la France, j'ai vu un chiffre 39 [...] J'avais l'impression que ce tableau durait quatre à cinq années [...] Après quoi, j'ai vu une France lumineuse et éclairant le monde ${ }^{44} »$. 

battre, se tuer, se déchirer, des foules immenses se sauvant des incendies, le feu descendant et courant sur la terre », le Christ vient la rassurer et lui dire : «Souffre, prie, c'est une expiation ». Horrifiée, elle ajoute, " personne ne pouvait comprendre la douleur que je portais, le poids sur mon âme ${ }^{45}$ ». Ainsi, sa future «mission» lui est clairement annoncée en songe par le Christ, Yvonne-Aimée est une "victime sacrificielle», elle « expie » les péchés d'une France coupable.

À partir du moment où la France entre effectivement en guerre, Mère Yvonne-Aimée subit un surcroît de "souffrances morales indicibles». En décembre 1940, elle écrit: «nous sommes toujours au calme, très protégées, cela ne veut pas dire que je ne vis pas sans souffrances. Je passe même une très dure période... ». Être réélue à la charge de Supérieure de la communauté est vécu par elle comme une souffrance. "Tout se passe bien, mais je souffre » indique régulièrement Yvonne-Aimée à son confesseur. Ou encore « je souffre, je souffre...mais je suis contente de souffrir ${ }^{46}$ ! ». Il n'est pas essentiel pour nous de savoir si ces afflictions sont réelles ou imaginaires, l'important réside dans le fait qu'elles sont soulignées et accentuées dans tous les ouvrages consultés. Le Père Barrai écrivait à propos d'Yvonne-Aimée dans son rapport destiné au Vatican : «Elle a un sens très vif de la souffrance pour acheter l'éternité bienheureuse pour elle et pour les âmes ${ }^{47}$ ».

La Mère Augustine assume donc sa mission de "victime » annoncée par le Christ dix-huit ans plus tôt. D'ailleurs, le 5 juillet 1942, le Christ lui apparaît pour la féliciter : « Tu m'as laissé torturer ton être de chair, expiant les fautes de mes fils aveugles, prenant sur toi d'expier leurs crimes, leurs passions, leurs lâchetés, leurs infidélités - et ton élan fut superbe ». Du Petit Roi d'Amour à Mère Yvonne-Aimée, nous passons d'un sacrifice symbolique à un sacrifice, sinon réel, du moins présenté comme tel. Dans leur ouvrage sur Yvonne-Aimée, les Augustines ne cessent d'insister sur son rôle de "messagère et de collaboratrice » du Jésus Roi d'Amour. La personne se substitue à l'image ; et un transfert de compétences semble s'opérer. Le sacrifice, affirme Jean-Pierre Albert, «prétend restaurer un ordre cosmique qui englobe aussi les sociétés et, de fait, il renforce symboliquement la cohésion des groupes ${ }^{48} »$. Cette mise en perspective sociale et symbolique du sacrifice permet de mieux comprendre pourquoi la souffrance est le maître mot des biographies d'Yvonne-Aimée. En temps de crise, une victime est nécessaire pour expier les fautes des hommes et, à terme, rétablir l'ordre.

Par ailleurs, la correspondance d'Yvonne-Aimée montre qu'en mai et juin 1940, elle interprète le conflit mondial comme un " châtiment de Dieu », conformément à la logique des partisans du culte du Sacré-Cœur. La France, coupable de préférer une société laïque à une société chrétienne, subit la justice divine et doit payer pour ses péchés. «La France expie son goût trop fort du plaisir, ses erreurs, ses insouciances » écrit Yvonne-Aimée à une amie le 29 mai 1940. Elle souhaite que la France revienne à des «sentiments plus chrétiens ». Dans une lettre du 17 juin 1940, elle explique à sa sœur et son beau-frère : "Malgré cette cessation des combats, la France n'est pas perdue, elle se relèvera quand Dieu aura jugé que l'humiliation qu'il lui a infligée aura porté ses fruits. [...] La France a beaucoup péché - et dans les meilleures familles, parmi les prêtres, les religieux, il n'y avait plus assez d'esprit de sacrifice, plus assez de vraie piété [...] Voilà ce qui a mérité le châtiment [...] Dieu veut que la France redevienne son peuple choisi. Elle le redeviendra, mais il faut l'obtenir ${ }^{49}{ }^{\prime}$. 
31 En affichant simultanément le Sacré-Cœur et l'Enfant Jésus, et en se posant elle-même comme une victime sacrificielle, Yvonne-Aimée semble adhérer au projet séculaire d'une partie des catholiques français qui rêvent d'une France " régénérée » et réconciliée avec Dieu. «Un jour viendra et j'espère, sans tarder où, plus fidèles, plus sacrifiés, plus renoncés, nous vivrons et jouirons pleinement dans une France renouvelée, la foi et la charité - notre vie religieuse ", écrit-elle ${ }^{50}$. En 1940, la Révolution nationale sous la devise «Travail, famille, patrie » semblait proche des aspirations chrétiennes et a ainsi conquis de nombreux catholiques français et la majorité du corps ecclésiastique. Le gouvernement de Vichy employait dans ses déclarations officielles un vocabulaire coutumier des militants catholiques. Le Maréchal Pétain était considéré comme l'homme providentiel qui allait enfin ramener la France à sa vocation chrétienne ${ }^{51}$. En 1943, un fanion brodé du Sacré-Cœur fut offert au maréchal qui l'accepta « avec bonheur ». Mère Yvonne-Aimée et son Petit Roi d'Amour offraient donc toutes les caractéristiques nécessaires pour rassembler les catholiques partisans du nouveau régime de Pétain. Pourtant, dès les premières années du conflit, l'Augustine prend une trajectoire radicalement opposée.

\section{Yvonne-Aimée dans la tourmente}

Contrairement aux très nombreuses «victimes " que compte l'histoire, Mère YvonneAimée ne se contente pas de souffrir sur son lit, enfermée dans sa cellule ${ }^{52}$. Si, comme nous l'avons évoqué précédemment, les «atroces souffrances» et les «attaques du démon » redoublent d'intensité, Yvonne-Aimée n'en est pas moins présente, activement engagée dans le conflit. En mai 1940, quand les divisions blindées d'Hitler envahissent la France, Yvonne-Aimée ouvre les portes du monastère de Malestroit aux réfugiés du Nord. « On va se tasser... Dieu donne à qui donne ! " s'exclame la religieuse avec son dynamisme et son humour habituel. Plus encore, de juin à août 1940, la clinique accueille des soldats, sous-officiers et officiers de l'armée du Nord. Déjouant la vigilance des Allemands, Yvonne-Aimée parvient à assurer le ravitaillement du couvent en utilisant les ambulances pour le transport et en entreposant les victuailles dans la salle de désinfection du soussol. En août 1940, un colonel de la Wehrmacht l'informe qu'il souhaite réquisitionner la clinique de Malestroit pour les seuls soldats allemands. Yvonne-Aimée refuse catégoriquement de « mettre dehors » ses malades, et le colonel finit par retirer son ordre de réquisition.

L'action d'Yvonne-Aimée est surtout sensible à partir de 1943. Le village de Malestroit est situé tout près du maquis de Saint-Marcel, haut lieu de la résistance bretonne. Les témoins directs ne tarissent pas d'anecdotes sur l'attitude de la religieuse pendant le second conflit mondial. Ils se plaisent à raconter la façon dont elle cachait les résistants et les ruses dont elle usait pour tromper les Allemands, le tout sur le ton de la plaisanterie. C'est sur le même ton que Mère Yvonne-Aimée relate les faits sur ses carnets en 1943 : « 25 mars! Quel cadeau, douce Vierge Marie, en ce jour de salut, de nous envoyer les Allemands pour une occupation ${ }^{53}$ ! ». À la fin de l'année 1944, elle écrit à ses sœurs dans la circulaire adressée aux maisons de l’Ordre : «Vous attendez des histoires ! ...oh ! il y en a, et d'assez amusantes, malgré le tragique du moment ${ }^{54} »$. Les années de guerre sont l'occasion de multiples manifestations de prodiges. « Nous avons dû pratiquer en grand la prestidigitation! ». Son don de bilocation lui permet d'aller porter secours aux soldats, aux prisonniers en détresse qui l'invoquent, un peu partout en France, sur terre et en 
mer. « Une fois, écrit Paul Labutte, plongée dans un recueillement profond, elle entendit des prières qui montaient de différents points du globe ».

À Malestroit, Yvonne-Aimée n'omettait aucun détails pour cacher les soldats et officiers alliés. Elle les installait dans des lits déjà chauds, plaçant ailleurs les véritables malades. Deux parachutistes blessés furent déguisés en «bonne sœur» avec la robe, le voile, la guimpe et intégrés aux prières de la communauté, à l'intérieur de la clôture, le temps des perquisitions allemandes. Le général Audibert, chef de la résistance de l'Ouest, a également trouvé asile à Malestroit. Finalement découvert par la Gestapo, il part en se mettant au garde-à-vous devant Yvonne-Aimée qu'il appelle " mon général ${ }^{55}$ ». Un témoin contemporain s'est souvenu, en passant devant la ferme que possédait la communauté, de la façon dont elle avait placé des résistants dans le double fond d'une charrette remplie de fumier. On pourrait ainsi multiplier à l'envi les exemples des actions de la religieuse pendant la guerre.

En apportant une aide active à la Résistance, Mère Yvonne-Aimée infirme les valeurs symboliques véhiculées par sa position de mystique souffrante d'une part et par son Petit Roi d'Amour de l'autre. Pour expliquer l'engagement presque «paradoxal » d'YvonneAimée, il faut bien admettre une part de contingence dans la rencontre entre le destin individuel de la religieuse et les circonstances politiques et historiques. Dès juin 1940, alors qu'elle parle dans ses lettres d'une "France châtiée ", d'un "monde déboussolé ", son sens de l'hospitalité et sa charité suffisent à expliquer qu'elle accueille à Malestroit les réfugiés et les soldats français. En revanche, son action ultérieure auprès des résistants semble avoir été quelque peu précipitée par les événements. En fait, à la fin du mois de janvier 1943, un Père qu'elle estimait beaucoup l'accuse d'être une «fausse mystique ». Il l'assimile à une abbesse du XVI ${ }^{\mathrm{e}}$ siècle vouée au diable, Madeleine de la Croix, et lui reproche son extraordinaire réussite dans tout ce qu'elle entreprend. Depuis trois ans, ce Père avait réuni un dossier accablant à son encontre et menaçait de le présenter devant un tribunal ecclésiastique. Le Père Crété, confesseur d'Yvonne-Aimée depuis plus de vingt ans, en vient lui aussi à douter d'elle. Enfin, le Père Monier-Vinard, théologien et spécialiste des états mystiques, écrit au même moment que la "réussite parfaite de tous ses projets» est une chose "étrange». Il qualifie de "dangereuse» l'atmosphère d'admiration, de vénération et de louanges autour de la religieuse. Atterrée et profondément choquée, Yvonne-Aimée se rend à «l'Oasis », à Paris ${ }^{56}$. Là, le 16 février 1943, elle est arrêtée par la Gestapo. Il ne s'agit pas d'insinuer une quelconque relation de cause à effet, nous supposons seulement que le cours des événements a finalement amené Yvonne-Aimée à se positionner clairement. Suspecte à l'autorité ecclésiastique et arrêtée par la Gestapo, la religieuse a dû, en quelque sorte, "choisir son camp ». Une fois « miraculeusement » libre et de retour à Malestroit, elle met toute son énergie au service de la Résistance ${ }^{57}$.

Le Père Labutte s'est demandé si Yvonne-Aimée faisait partie des réseaux de la Résistance et a répondu par la négative. Pour lui, Yvonne-Aimée n'a suivi qu'une seule ligne de conduite, sa devise Tout droit au service de Jésus Roi. «À l'occasion, elle rendait des services à la cause de la libération de la France, dit-il, ses missions au service du Roi Jésus pouvaient coïncider parfois avec les objectifs de la Résistance». Face à l'attitude ambiguë des catholiques pendant l'occupation, Yvonne-Aimée a apporté un «témoignage chrétien et français irrécusable ${ }^{58} »$. Les convictions politiques d'Yvonne-Aimée sont difficiles à connaître. Nous pouvons seulement tenter de les appréhender à travers les réalisations et les actes de la religieuse. Symboliquement, le Petit Roi d'Amour, s'il s'apparente au culte du 
Sacré-Cœur, s'en écarte sensiblement, nous l'avons évoqué. Personnellement, YvonneAimée se place dans la longue lignée des mystiques souffrantes, mais elle s'en distingue par un dynamisme hors du commun. À peine acceptée comme religieuse à Malestroit, elle s'évertue à faire rénover la clinique du couvent, dessine les plans pour un nouveau réfectoire et propose une révision des Constitutions des sœurs augustines - le texte datait de 1631 -. Par la dévotion qu'elle promeut et les initiatives qu'elle propose, les idées qu'elle avance et le comportement qu'elle adopte, Yvonne-Aimée ne cesse d'associer des aspects contradictoires.

\section{Une héroïne nationale?}

37 «Yvonne Beauvais, fondatrice d'une fédération de religieuses contemplatives et hospitalières, reconnue comme hérö̈ne nationale par de Gaulle qui tint à la décorer personnellement, resta vingt-cinq ans dans l'ombre. [...] ». C'est ainsi qu'est présentée la religieuse dans le journal Le Figaro daté du 24 mars 1987, à l'occasion de la publication de ses Écrits spirituels et de ses Prédictions par René Laurentin. Il faut en effet préciser qu'immédiatement après le dénouement du second conflit mondial, les autorités politiques se sont manifestées pour témoigner à Yvonne-Aimée toute leur gratitude. Le 24 juin 1945, à Saint-Marcel, elle reçoit la Croix de Guerre avec palme des mains du général Allard, en présence du ministre de la Guerre du gouvernement provisoire de la République française, Monsieur Diethlem. À cette occasion, elle est saluée comme une «femme d'un courage et d'un dévouement extraordinaires ». Le 22 juillet 1945, à Vannes, le général de Gaulle en personne lui remet la Légion d'honneur, « au son des cloches, des fanfares et des applaudissements ». Le 3 janvier 1946, la Médaille de la Résistance et la Médaille de la Reconnaissance Française lui sont décernées. Le 7 août 1949, la clinique de Malestroit reçoit la Croix de Guerre. Une plaque commémorative est toujours visible sur un de ses murs. Ajoutons encore la King's Medal for Courage in the Cause of Freedom décernée par l'Angleterre, et la Medal of Freedom américaine accompagnée d'un diplôme paraphé par le général Eisenhower.

38 La photographie du général de Gaulle remettant la légion d'honneur à Yvonne-Aimée est restée célèbre. La sœur, toute de blanc vêtue avec la guimpe noire, voit le "grand officier » la décorer solennellement ${ }^{59}$. René Laurentin précise que le général fit passer la religieuse avant un officier présent pour recevoir la même décoration. De plus, au moment de lui remettre la légion d'honneur, il se découvrit devant elle et lui dit: «Je vous remercie au nom de la France ${ }^{60} \%$. L'action d'Yvonne-Aimée est officiellement reconnue par les dignitaires de la République française.

En 1956, quand les sœurs augustines décident d'écrire un ouvrage sur leur célèbre supérieure, elles font précéder le chapitre qui détaille ses visions prophétiques sur la guerre et son action pendant le conflit, par une introduction véhémente. "Nous n'avons pas le droit de refuser au Seigneur Jésus d'intervenir dans le temporel quand Il Lui plait et comme Il Lui plait et de superposer aux querelles des hommes, par l'intermédiaire d'une créature de son choix, Sa Puissance Miséricordieuse. Il faudrait alors Lui tenir rigueur de l'un ou l'autre côté de la barricade, d'avoir à travers les siècles, décidé de mener dans le temps, une politique d'intervention dans les affaires intérieures d'un pays et d'y avoir suscité des héroïnes nationales ». Leur bienfaitrice est donc explicitement désignée comme une héroïne nationale, ce que semble cautionner le gouvernement français. Mais, la place même de ce texte et la détermination qui s'en dégage montrent que les sœurs 
cherchent, en quelque sorte, à justifier le bien-fondé de l'attitude d'Yvonne-Aimée. Elles veulent prévenir le lecteur afin qu'il ne soit pas étonné de son action pendant la guerre et de sa «mission ». Comme si cette dénomination en terme d'héroïsme national avait été contestée. Pourquoi une religieuse ne pourrait-elle pas être un héros? semblent demander les Augustines. C'est dans le passé qu'elles vont chercher une réponse à cette question. «Sans vouloir pour l'instant forcer la comparaison, l'Église, dans sa liturgie, a fait siennes par exemple, les déclarations de la Pucelle de Domrémy, dont l'essentiel revenait à dire que l'aventure de cette enfant prédestinée avait été mise par Dieu au service d'une cause d'allure temporelle. L'ignorer, ce serait peut-être refuser d'admettre, contre toute évidence que chaque peuple a sa mission fixée par la Providence et que Celle-ci a le droit de s'y faire sentir ${ }^{61}$.»

Le cadre est posé, Yvonne-Aimée est placée dans le droit fil d'une héroïne nationale incontestée celle-ci : Jeanne d'Arc. Cette visionnaire du Moyen Âge devient au XIXe siècle une figure du consensus. Elle rassemble, en effet, les laïcs et les religieux ; l'État et l'Église. En 1841, après quatre siècles de silence, Michelet s'enthousiasme pour elle. La Pucelle d'Orléans a droit à des pages exaltées dans son Histoire de France. Elle est célébrée comme une figure populaire qui s'est engagée pour son pays. Face à ce processus d'héroïsation laïque, l'Église riposte et Monseigneur Dupanloup fait son panégyrique en 1869. Dès lors, elle suscite un intérêt toujours plus grand du côté des républicains comme chez les catholiques conservateurs. En mai 1920, suite à un spectaculaire revirement de position de la part de l'Église, Jeanne d'Arc est canonisée. C'est la « sainte de la Patrie ${ }^{62}$ ».

En choisissant Jeanne d'Arc comme référence, les Augustines de Malestroit activent donc chez les laïcs comme chez les catholiques un nationalisme d'autant plus exacerbé que la France sort du conflit mondial. Au début du $\mathrm{XX}^{\mathrm{e}}$ siècle, Jeanne d'Arc est entièrement repensée dans les termes nouveaux de « héros national ». La figure du héros appartient, en effet, à la modernité. Elle apparaît dans le contexte des nations, de la république. Le héros s'épanouit dans une situation de crise et est d'autant plus considéré qu'il est physiquement et moralement éloigné de la sphère des valeurs temporelles. YvonneAimée, comme Jeanne d'Arc, semblent avoir toutes les qualités requises pour être qualifiées d'héroïnes nationales: ce sont des femmes, elles ne se préoccupent officiellement que de spirituel, et interviennent paradoxalement dans un contexte belliqueux. L'excessif décalage entre le rôle et l'identité est un facteur primordial dans l'élaboration de l'archétype du héros national ${ }^{63}$. Il était effectivement difficile de présumer qu'une religieuse d'un petit village de Bretagne serait appelée à jouer un rôle dans la Seconde Guerre mondiale.

Entre saintes et héroïnes nationales, la limite est donc ténue en cette première moitié du $\mathrm{XX}^{\mathrm{e}}$ siècle. Comme le souligne Anne Eriksen, la religion est un « champ prometteur » pour l'héroïsme féminin. Elle « offre aux femmes des occasions et un rayon d'action qu'elles ne trouvent nulle part ailleurs ${ }^{64} »$. Mère Yvonne-Aimée, dans sa singularité, se situe au confluent de deux formes d'héroïsme. En se présentant, dès 1922, comme la victime désignée par Dieu pour expier les fautes de la nation, elle entre dans le cadre d'un héroïsme "passif" salutaire. La victime revêt une dimension éminemment sociale puisqu'elle œuvre pour le bien de tous. En revanche, en apportant un soutien concret pendant le conflit mondial, Yvonne-Aimée est projetée dans la sphère de l'héroïsme « actif» qui rompt avec l'idéal de la religieuse humble, passive et soumise. Mais, son précepte Tout droit au service du Roi d'Amour vient légitimer son comportement peu convenable. 

Gaulle, valorise l'action de la religieuse avec faste. Cette éclatante reconnaissance souligne aux yeux de tous que la collaboration au gouvernement de Pétain n'a pas été générale chez les catholiques français. En remettant la légion d'honneur à Yvonne-Aimée, le général de Gaulle illustre le fait qu'être catholique et partisan de la France libre et républicaine est une réalité. Loin d'écarter l'Église pour ses erreurs passées, le nouveau gouvernement pardonne et prouve sa bonne foi en honorant une de ses représentantes. Pendant des siècles, par l'intermédiaire du sacre, l'Église a conféré aux rois de France une dimension transcendante inaltérable. Inversement, au lendemain de la Seconde Guerre mondiale, c'est l'État qui, en quelque sorte, cherche à légitimer l'Église et s'assurer de son soutien par des cérémonies officielles et des décorations républicaines.

dévotion à l'Enfant Jésus est politiquement moins marquée en ce milieu de $\mathrm{XX}^{\mathrm{e}}$ siècle. Le Petit Roi d'Amour d'Yvonne-Aimée apparaît comme une figure paradoxale à l'image de la religieuse elle-même. Sa vocation de "souffrante" traditionnelle est en rupture complète avec son dynamisme et son esprit novateur, nous l'avons souligné. En 1935, son projet de Fédération des Augustines hospitalières de la miséricorde de Jésus est une absolue nouveauté. Cette initiative hétérodoxe est tout d'abord rejetée par les autorités ecclésiastiques. Une telle formule n'est même pas envisagée dans le droit canon dans le cas des couvents de femmes. Ce n'est qu'au prix d'une farouche obstination que la Fédération voit le jour au lendemain du conflit mondial.

Il reste à préciser qu'Yvonne-Aimée, "héroöne nationale " de son vivant, n'a pas été reconnue sainte ni bienheureuse par l'Église. Le processus ne s'est pas accompli jusqu'au bout. Yvonne-Aimée meurt en 1951, bénéficie d'un enterrement en grandes pompes, mais son procès de béatification est définitivement arrêté en 1960, nous l'avons dit. Les raisons de ce rejet total sont assurément multiples et complexes. Yvonne-Aimée et son Petit Roi d'Amour entraient pourtant dans le moule façonné depuis des siècles par l'Église. Cependant, au milieu du XXe siècle, la fonction de victime sacrificielle n'est plus tolérable sous sa forme littérale. Yvonne-Aimée adhère à une tradition dont l'Église, à la veille du concile de Vatican II, cherche à s'écarter. Elle renvoie à l'Institution un reflet désuet. Pourtant, la reconnaissance de l'État français aurait pu infléchir les positions de l'Église. Il n'en fut rien. Comme si l'Église cherchait d'autant plus à augmenter la distance qui la sépare de l'État laïque et retrouver sa vocation universelle. Yvonne-Aimée héroïne nationale célébrée par la République, n'est plus acceptable par l'Église. Elle est victime d'un excès de conservatisme d'une part et d'un excès de modernité de l'autre. Seul son Petit Roi d'Amour, dont la dévotion a été étendue à l'Église universelle par Jean XXIII en 1958, lui survit.

\section{BIBLIOGRAPHIE}

ALBERT Jean-Pierre, Le sang et le ciel. Les saintes mystiques dans le monde chrétien, Paris, Aubier, 1997. Albert Jean-Pierre, « Saintes et héroïnes de France, entre l'Église et la République », Terrain, 30, mars 1998, pp. 113-124.

Archives de sciences sociales des religions, 113 | janvier-mars 2001 
ALBERT Jean-Pierre, « Du martyr à la star. Les métaphores des héros nationaux », in Pierre Centlivres, Daniel Fabre, Françoise Zonabend, La fabrique des héros, Paris, Édition de la Maison des Sciences de l'Homme, 1999, pp. 11-32.

***, Au service de Jésus Roi d'Amour, Rennes, Monastère de Malestroit, 1956.

BAINVEL J.V., La dévotion au Sacré-Cour de Jésus, Paris, Beauchesne, 1921.

BARRAL Louis, Marie-Yvonne-Aimée de Jésus Beauvais, Rennes, Monastère de Malestroit, 1956.

ВIOT René, L'énigme des stigmatisés, Paris, Fayard, 1955.

BREMOND Henri, Histoire littéraire du sentiment religieux en France depuis la fin des guerres de religion jusqu'à nos jours, Paris, Bloud et Gay éditeurs, 1921, vol III.

CHOLVY Gérard, HILAIRE Yves-Marie, Histoire religieuse de la France contemporaine, t. III : 1930-1988, Toulouse, Privat, 1996.

CORBLET Jules, Histoire dogmatique, liturgique et archéologique du sacrement de l'Eucharistie, Paris, Société générale de Librairie Catholique, 1885, t. I et II.

DANEMARIE Jeanne, Les mystères des stigmatisés. De Catherine Emmerich à Thérèse Neumann, Paris, Grasset, 1933.

DARRICAU Raymond, Peyrous Bernard., éd., Sainte Marguerite-Marie Alacoque et le message de Parayle-Monial, Paris, Desclée de Brouwer, 1993.

***, « Jésus Roi d'Amour. Interview du Père Paul Labutte, fils spirituel d'Yvonne-Aimée de Malestroit », Feu et Lumière, n 108, juin 1993, pp. 10-17.

DUQUESNE Jacques, Les catholiques français sous l'occupation, Paris, Grasset, 1966.

ERICKSEN Anne, « Être ou agir ou le dilemme de l'hérö̈ne », in CENTLIVRES Pierre, fABRE Daniel, zONABEND Françoise, La fabrique des héros, Paris, Éditions de la Maison des Sciences de l'Homme, 1999, pp. 149-164.

FABRE-VASSAS Claudine, La bête singulière. Les juifs, les chrétiens et le cochon, Paris, Gallimard, 1994. GLOTIN Édouard. « Réparation », Dictionnaire de Spiritualité Ascétique et Mystique, Paris, Beauchesne, 1987, t XIII, col. 369-413.

HAMON Auguste, Histoire de la dévotion au Sacré-Cœur, Paris, Beauchesne, 1923, 5 volumes.

HENRI-OLIVIER L., Le mois du Roi d'Amour, Avignon, Aubanel Frères, 1922.

LABUtTe Paul, Yvonne-Aimée de Jésus, « Ma Mère selon l'esprit », Paris, F.-X. de Guibert, 1997.

LAURENTIN René, MAHÉO Patrick, Les stigmates d'Yvonne-Aimée de Malestroit dans le sillage de saint François d'Assise, Paris, F.-X. de Guibert, 1987.

LAURENTIN René, Yvonne-Aimée de Malestroit, un amour extraordinaire, Clamecy, F.-X. de Guibert, 1995, (1 1 ère édition 1985).

LEBRUN François, dir., Histoire des catholiques en France, Paris, Privat, 1980.

LE BRUN Jacques, « Politique et spiritualité : la dévotion au Sacré-Cœur à l'époque moderne », Concilium, $n^{\circ} 69,1971$, pp. 25-36.

LE BRUN Jacques, « Marguerite-Marie Alacoque », Dictionnaire de Spiritualité Ascétique et Mystique, Paris, Beauchesne, 1977, vol X, col 349-355. 
LE BRUN Jacques, «A corps perdu. Les biographies spirituelles féminines du XVII ${ }^{e}$ siècle », in MALAmoud Charles, VeRnANT Jean-Pierre, Le temps de la réflexion, t VII : « Corps des dieux », Paris, Gallimard, 1986, pp. 389-408.

LE BRUN Jacques, « La dévotion à l'Enfant Jésus au XVII e siècle », in BECCHI E., JULIA D., Histoire de l'enfance en Occident, t. I : De l'Antiquité au XVII ${ }^{\mathrm{e}}$ siècle, Paris, Seuil, 1998, pp. 402-431 (1 ère édition en italien 1996).

LEMIUS J.-B., Les grands desseins du Sacré Coeur de Jésus et la France, Paris, Librairie S. Paul, 1915. LÉVI-STRAuss Claude, « Le Père Noël supplicié », Les Temps Modernes, Paris, 1952, vol. 7, n 77, pp. 1572-1590.

MAÎTRE Jacques, Les stigmates de l'hystérie et la peau de son évêque, Laurentine Billoquet (1862-1936), Paris, Anthropos, 1993.

MÂLE Émile, L'art religieux du XIIIe siècle en France, Paris, Armand Colin, 1948.

MANZONI Giuseppe, « Victimale (spiritualité) », Dictionnaire de Spiritualité Ascétique et Mystique, Paris, Beauchesne, 1994, t XIV, col 531-545.

PLAQUEVENT Jean, L'imitation du petit Jésus, Paris, Seuil, 1948.

ROSENBAUM-DONDAINE Catherine, Un siècle d'images de piété. L'image de piété en France, 1814-1914, Paris, Musée-Galerie de la SEITA, 1984.

SINANOGlou Leah, "The Christ-Child as sacrifice : a medieval tradition and the Corpus Christi plays", Speculum, juillet 1973, vol. XLVII, n³ 3, pp. 491-509.

Thérèse de Lisieux, Euvres complètes, Paris. Cerf/Desclée de Brouwer, 1997.

TUBACH Frédéric C, Index Exemplorum. A Handbook of Medieval Religious Taies, Helsinki, 1969. FFC 204. VIRCONDELET Alain, Le monde merveilleux des images pieuses, Paris, Hermé, 1988.

YounG Karl, The Drama of the Medieval Church, 2 vol., Oxford, Oxford University Press, 1933.

\section{NOTES}

1. Les articles les plus récents consacrés à l'Enfant Jésus soulignent le caractère politique et national des différentes dévotions qui lui sont attachées. Voir à ce sujet Jacques LE BRUN, 1998, p. 419.

2. Le Père Labutte a connu Mère Yvonne-Aimée à l'âge de 19 ans. C'est elle qui est à l'origine de sa vocation de prêtre. L'ouvrage a pour titre : Yvonne-Aimée de Jésus, «ma mère selon l'esprit ».

3. Pour une analyse de l'écriture chez les saintes et les mystiques, voir Jean-Pierre ALBERT, 1997, chap. IX, pp. 357-400 et Jacques LE BRUN, 1986, pp. 389-408.

4. Au service..., 1956, pp. 42-44.

5. Paul LABUTTE, 1997, p. 55. Yvonne cherche surtout à dompter sa gourmandise et sa propension à désobéir.

6. René LAURENTIN, 1995, p. 33.

7. Jean-Pierre ALBERT, 1997, p. 388.

8. Je renvoie ici à l'ouvrage de Jean-Pierre ALBERT précédemment cité, pp. 138-148. Nombreux textes autobiographiques du XIX ${ }^{\mathrm{e}}$ et du début du XX $\mathrm{X}^{\mathrm{e}}$ siècle dépeignent une jeune fille privée d'un milieu familial complet, qui apprend à comptabiliser ses mortifications et dont la première communion est vécue comme une expérience inoubliable. 
9. Louis BARRAL, 1956, pp. 182-186.

10. C'est précisément dans l'article intitulé "stigmates» que le nom d'Yvonne-Aimée est mentionné dans le Dictionnaire de spiritualité ascétique et mystique, 1990, tome XIV, col 1225. L'auteur indique que ces stigmates apparaissaient chaque vendredi à divers endroits du corps. Il est précisé que le fait, bien qu'attesté par plus de quatre-vingt-dix témoins, n'a pas été prouvé de façon scientifique. Voir aussi René LAURENTIN et Patrick MAHÉO. 1987. Sur les stigmatisés, Jacques MAÎTRE, 1993, René BIOT. 1955 et Jeanne DANEMARIE, 1933.

11. Par exemple, "Joujou se marie », 1924, Plon, signé du pseudonyme « Dyvonne ».

12. Au service..., op. cit., p. 206. René LAURentin, op. cit., p. 77 et Paul LABUTTE, op. cit., pp. 169-170. Yvonne Bato est l'amie d'Yvonne-Aimée. C'est elle qui, par l'intermédiaire de sa sœur, Mère Madeleine du Sacré-Cœur, l'a fait entrer à Malestroit après sa paratyphoïde. Mlle Bato est fille de saint François de Sales.

13. Des cas de guérisons miraculeuses après une seule prononciation de l'invocation sont rapportés dans Au service..., op. cit., pp. 212-213.

14. Ibid., p. 218.

15. Se référer par exemple à François LEBRUN, 1980, p. 514 et plus généralement Gérard CHOLVY et Yves-Marie HILAIRE, 1996, t III.

16. René LAURENTIN, op. cit., p. 70.

17. Certes l'Enfant Jésus lui apparaît entre 1922 et 1926, mais il s'agit du nouveau-né de la crèche qu'elle appelle petit Jésus et en aucun cas Roi d'Amour.

18. Cette phrase est reproduite sur la feuille explicative de la dévotion au Petit Roi d'Amour que remettent les Augustines de Malestroit en complément des images.

19. C'est le petit Jésus qui lui sourit dans la crèche peu avant sa communion. C'est encore à lui qu'elle adresse son pacte de sang. Mais à cette époque, l'Église proposait volontiers aux jeunes chrétiens l'Enfant Jésus comme compagnon moralisateur.

20. René LAURentin, op. cit., pp. 68-69 et Paul LABUtTe, op. cit., pp. 646-647.

21. Thérèse de Lisieux, 1997, Manuscrit B, p. 220, Manuscrit C, pp. 237-238 et Poésies, pp. 744-748. L'Enfance spirituelle n'apparaît pas avec sainte Thérèse de Lisieux. Elle se façonne au début du $\mathrm{XVII}^{\mathrm{e}}$ siècle sur les notions d'abandon, d'anéantissement et d'abnégation. La "petite sainte ", avec ses mots simples, la met à la portée de tous. Je renvoie à l'article de François-Marie BERROUARD, François DE SAINTE-MARIE et Charles BERNARD, «Enfance spirituelle» dans le Dictionnaire de Spiritualité, 1959, t IV / 1, col. 682-714.

22. Entretien dans le mensuel catholique Feu et Lumière, n 108, juin 1993, p. 13.

23. J'ai pu travailler, entourée de bienveillance, sur la centaine d'images pieuses que possède le Musée Paul Dupuy à Toulouse, ainsi qu'à l'Institut Catholique de Toulouse.

24. Jean PLAQUEVENT, 1948, p. 100. L'ouvrage, publié pour la première fois en 1932, est sans cesse réédité jusqu'en 1962.

25. Voir par exemple l'ouvrage de Alain VIRCONDELET, 1988, ainsi que le catalogue d'exposition intitulé Un siècle d'images de piété. L'image de piété en France 1814-1914, 1984.

26. Henri BREMOND, 1921, p. 575.

27. Ibid., p. 581.

28. Cité par Émile MÂLE. 1948, p. 362.

29. Leah SinANoglou, 1973, p. 501. Voir aussi Karl YounG, 1933, vol II, pp. 3-125.

30. Voir F. C. тUBACH, 1969, entrée " Christ-child », et Jules CORBLET, 1885, t I, pp. 468-487.

31. Au sujet des juifs et du thème de "l'hostie-Enfant " au XIII ${ }^{\mathrm{e}}$ siècle, voir l'ouvrage de Claudine FABRE-VASSAS, 1994, pp. 174-177.

32. Claude LÉVI-STRAUSS, 1952, p. 1584.

33. L HENRI-OLIVIER, 1922. 
34. La dévotion au Sacré-Cœur est particulièrement active et présente au début du siècle, il suffit de s'arrêter sur les dates de publication des ouvrages existants pour s'en convaincre. Par exemple, dans la seule bibliothèque de l'Institut Catholique de Toulouse, la grande majorité des ouvrages consacrés à Marguerite-Marie Alacoque et au Sacré-Cœur datent des années 1920-1930. Il existe à la même époque de très nombreux manuels de dévotion.

35. Nous nous permettons de renvoyer aux ouvrages de J-V. BAINVEL, 1921, Auguste HAMON, 1923-1940 en 5 volumes, Jacques LE BRUN, 1977, vol X, col 349-355 et récemment les actes du colloque à l'occasion du tricentenaire de la mort de sainte Marguerite-Marie Alacoque, Raymond DARRICAU et Bernard PEYROUS, 1993.

36. J. V. BAINVEL, op. cit., chap. II, pp. 20-46 et p. 51. Les termes entre guillemets sont ceux des lettres de révélations laissées par Marguerite-Marie.

37. Voir les articles de G. MANZoNI, 1994, «Victimale (spiritualité) », t. XIV, col. 531-545 et Édouard GLotin, 1987, « Réparation », t. XIII, col. 369-413 dans le Dictionnaire de Spiritualité.

38. Jacques LE BRUN, 1977, col. 349-355.

39. Raymond DARRICAU et Bernard PEYROUS, op. cit., pp. 269-290.

40. J.-B. LEMIUS, 1915, Préface III-XIII.

41. J. V. BAINVEL, op. cit., p. 583.

42. Jean-Pierre ALBERT, 1998, p. 125.

43. René LAURENTIN, op. cit., p. 65.

44. Ibid., p. 86 et $A u$ service..., op.cit., p.147. Ces prophéties entre dans un corpus que l'abbé Laurentin a eu l'autorisation de publier en 1987 sous le titre Prédictions.

45. Paul LABUTte, op. cit., p. 192.

46. Au service..., op. cit., pp. 149, 152 et 159 .

47. Louis BARRAL, 1956, p. 155.

48. Jean-Pierre ALBERT, op. cit., p. 66. Les questions du sacrifice et des victimes sacrificielles sont abordées dans les pages 63-69 et 338-343.

49. Paul labutTe, op. cit., p 524.

50. Ibid., p. 525, lettre datée du 30 juin 1940.

51. Jacques DUQUESNE, 1966, pp. 29-31. Il précise qu'à l'époque, l'un des mots d'ordre était « Nous avons péché ".

52. L'article de Giuseppe MANZONI, "Victimale (spiritualité)» du Dictionnaire de Spiritualité énumère ces nombreux mystiques ou laïcs, hommes ou femmes, qui se sont offert en victimes, op. cit., col. 540-544.

53. René LAURENTIN, op. cit., p. 177.

54. Au service..., op. cit. p. 169.

55. Sur l'attitude d'Yvonne-Aimée pendant l'occupation d'après ses écrits et les témoins directs dont le Père Labutte lui-même, lire Paul LABUTTE, op. cit., pp. 521-625.

56. Ce petit prieuré fut ouvert dans le quartier d'Auteuil par Mère Yvonne-Aimée en novembre 1941 pour permettre aux jeunes religieuses de l'Ordre de préparer leurs diplômes d'hospitalières. Ayant pour vocable Notre-Dame de la Consolation, il fut baptisé « l'Oasis » par Yvonne-Aimée qui $\mathrm{y}$ avait une chambre et un bureau. L'Oasis servait, à l'occasion, de refuge temporaire aux résistants, Ibid., pp. 544-548.

57. Yvonne-Aimée apparaît au Père Labutte le 17 février à 21 heures dans son bureau de la rue du Bac, traumatisée, en sang, sans qu'aucune porte ait été ouverte. Ibid., pp. 569-573.

58. Ibid., pp. $565 ; 634$.

59. Cette expression est issue du carnet d'Yvonne-Aimée. En 1929, elle eut une vision. Elle se voyait « devant la clinique avec sur la poitrine épinglées quatre ou cinq médailles [...] Un grand officier vint vers moi me saluer »; Ibid., p. 383.

60. René LAURENTIN, op. cit., p. 182. 
61. Au service..., op. cit., pp. 145-146.

62. Jean-Pierre ALBERT, 1998, pp. 118-121. Jean-Pierre Albert apporte une nuance importante à cet aspect consensuel autour de Jeanne d'Arc. Il affirme très justement que le personnage a été «trop nettement annexé par les cléricaux et les nationalistes d'extrême-droite pour pouvoir devenir du jour au lendemain le symbole d'une France réconciliée ».

63. Jean-Pierre ALBERT, 1999, p. 25.

64. Anne ERICKSEN, 1999, pp. 153-155.

\section{RÉSUMÉS}

À la veille du second conflit mondial, une Augustine hospitalière du Morbihan, Yvonne-Aimée de Malestroit (1901-1951), promeut le culte du Petit Roi d'Amour. Depuis la fin du Moyen Âge, et surtout à partir du XVII ${ }^{\mathrm{e}}$ siècle, la dévotion à l'Enfant Jésus a une dimension politique très nette. À travers les notions de "spiritualité victimale » et de «logique sacrificielle ", l'Enfant Jésus véhicule - comme le culte du Sacré-Cœur auquel il est partiellement lié - l'idée d'un retour à une France catholique et monarchique. Quant à Mère Yvonne-Aimée, elle est désignée par Dieu pendant la guerre pour " expier » les fautes des hommes pécheurs. Elle interprète le deuxième conflit mondial comme un «châtiment de Dieu» et rêve d'une France "régénérée " et « réconciliée avec Dieu ». Tout portait donc la religieuse à adhérer à la Révolution nationale du maréchal Pétain qui dénonçait une «France pécheresse» et parlait de «réparations nécessaires ». Pourtant, dès les premiers jours du conflit, Yvonne-Aimée soutient activement les réseaux de résistance bretons, au point de recevoir le 22 juillet 1945 la légion d'honneur des mains du général de Gaulle. La mystique devient une « héroïne nationale ». En revanche, l'Église, en 1960 - à la veille de Vatican II - suspend son procès de béatification et désavoue sans appel l'héroïne.

Just before the second world war, an hospitaller Augustinian of Morbihan, Yvonne-Aimée de Malestroit (1901-1951), promotes the devotion to the Little King of Love. Since the end of the Middle Age, and especially from the XVIIth century, the devotion to the Christ Child has a political dimension. Through notions of "victimale spirituality" and "sacrificial logic", the Christ Child brings - like the cult of Bled-Heart to which it is particularly linked - the idea of a return to a catholic and monarchic France. As for Yvonne-Aimée, God calls her during the war to "expiate" offences of a sinner humanity. Indeed she interprets the war like "God's punishment". Therefore, Yvonne-Aimée and her devotion are really in agreement with the marshal Pétain National Revolution which denounced a "sinner France" and talk about "necessary reparations". However, as soon as the war begins, Yvonne-Aimée supports resistance networks in Brittany, and then receives in 1945 the Legion of Honour from the general De Gaulle himself. The mystic becomes a "national heroine". In return, in 1960 the Church - at Vatican II eve - suspends her beatification proceedings and denies the heroine.

En vísperas del segundo conflicto mundial, una Augustiniana hospitalaria del Morbihan, YvonneAimée de Malestroit (1901-1951) promeve el culto del Pequeño Rei de Amor. Desde el fin de la Edad Media, y sobre todo a partir del siglo XVII la devoción al Niño Jesús tiene una dimensión política muy clara. A través de las nociones de "spiritualidad victímala" y de "lógica sacrifíciala", el Niño Jesús transmite -como el culto del Sagrado Corazón al cual está particularmente atado- la 
idea de un regreso a una Francia católica y monárquica. En cuanto a la Madre Yvonne-Aimée, está designada por Dios durante la guerra para "expiar" las faltas de los hombres pecadores e interpreta el segundo conflicto mundial como un "castigo de Dios". Así Madre Yvonne-Aimée parece adherirse a la Revolución Nacional del mariscal Pétain que denunciaba une "Francia pecadora" y hablaba de "reparaciones necesarias". Sin embargo, desde los primeros días del conflicto, Yvonne-Aimée sostiene activamente las redes de Resistancia en Bretaña, hasta recibir, el 22 de julio del 1945, la Legión de Honor de los manos del General de Gaulle. La mística llega a una "heroína nacional". En cambio, en 1960, la Iglesia -en vísperas de Vatican II- suspende su proceso de beatificación y renega la heroína.

\section{AUTEUR}

\section{SANDRA LA ROCCA}

Centre d'Anthropologie - Toulouse 